\title{
MODIFIKASI SELEKSI EAR TO ROW MENJADI SELEKSI SPIKE TO HOLE PADA GANDUM AUSTRALIA
}

\author{
Surya Seno Pamungkas*, dan Djoko Murdono \\ Universitas Kristen Satya Wacana \\ Gedung Dipo 66 Jalan, Diponegoro 66 Salatiga 50711 \\ *512014049@student.uksw.edu
}

\begin{abstract}
Abstrak
Penelitian ini melakukan modifikasi seleksi "ear to row" pada jagung yang diubah menjadi "spike to hole" untuk penyesuaian pada tanaman gandum. Modifikasi yang dilakukan bertujuan untuk mengidentifikasi sekaligus menyeleksi dan mengelompokan potensi benih gandum Australia yang didapat dengan metode ini. Hasil dari penelitian ini disajikan dalam bentuk data deskriptif disertai gambar dokumentasi tanaman gandum Australia yang ditanam dalam penelitian ini. Setidaknya didapatkan 4 tipe gandum Australia yang berpontesi untuk dikembangkan pada iklim tropis Indonesia. Keempat tipe gandum yang didapat dalam penelitian ini memiliki kode tipe 1 , tipe 2 , tipe 1a, dan tipe 2a. Perbedaan keempat tipe gandum Australia dalam penelitian ini terlihat secara visual, yaitu pada tipe 1 memiliki warna malai tua berwarna kuning pucat sedangkan pada tipe 2 memiliki warna kuning emas yang terlihat lebih pekat. Pada tipe 1 dan tipe 2 juga memiliki umur panen pada 113HST lebih awal disbandingkan tipe 1a dan tipe 2a. Secara visual tipe 1a dan tipe 2a memiliki ciri yang serupa dengan tipe 1 dan tipe 2 , hanya saja pada umur panen gandum tipe 1a dan 2a lebih lamat 14 hari yaitu pada $127 \mathrm{HST}$.
\end{abstract}

Kata Kunci : Gandum Australia, Gandum Tropis, Tongkol ke Baris

Submit: 8 April 2021 * Revisi: 16 April 2021 * Accepted: 25 April 2021 * Publish: 10 Mei 2021 


\section{PENDAHULUAN}

Uji coba penanaman benih gandum yang berasal dari biji gandum konsumsi dari Australia yang dilakukan oleh Pusat Studi Gandum FPB UKSW pada tahun 2019 pada wilayah tropis, menghasilkan biji gandum yang cukup bagus. Meskipun nilai keseragaman benih tersebut cukup rendah, hasil penanaman benih gandum konsumsi dari Australia tersebut setidaknya memiliki 3 kelompok yang terlihat. Potensi benih gandum yang diperoleh dari hasil uji coba tersebut diharapkan mampu menciptakan atau mendapatkan benih gandum tropis baru yang lebih berkualitas dan memiliki hasil produksi yang tinggi.

Proses pemanenan hasil uji coba benih gandum Australia pada tahun 2019 tidak dirontokkan melainkan disimpan dalam bentuk malai. Malai hasil panen tersebut dapat dijadikan materi genotipe yang baru jika dilakukan seleksi secara berkesinambungan. Metode seleksi untuk mendapatkan materi genetik yang seragam adalah metode "ear to row" yang dilanjutkan "row to block. Metode yang diterapkan merupakan modifikasi atau penyesuaian metode seleksi genotipe yang dilakukan pada tanaman jagung.

Metode seleksi genotipe benih gandum Australia pada pentlitian ini melakukan modifikasi pada seleksi genotipe jagung dengan melakukan penanaman biji tongkol jagung pada satu baris tanam. Modifikasi dilakukan karena tanaman gandum tidak bertongkol, melainkan bermalai atau spike sehingga metode seleksi disebut "spike to hole". Hole atau Lubang tanam yang diterapkan pada seleksi ini dimaksudkan untuk menyesuaikan jumlah biji pada malai gandum yang tidak sebanyak biji pada tongkol jagung.
Jumlah biji gandum dalam satu malai berkisar antara 20 hingga 40 biji gandum. Berdasarkan jumlah biji pada gandum dalam satu malai yang dapat ditanam dalam satu lubang tanam, dapat meningkatkan efektivitas pengendalian gulma dengan pemasangan mulsa plastik pada bedengan. Hal tersebut bertujuan untuk menurunkan tingkat kompetisi pada tanaman gandum yang diakibatkan gulma yang berpotensi tumbuh pada bedengan. Terjadinya kompetisi pada tanaman gandum yang akan diseleksi akan mengakibatkan penurunan tingkat pertumbuhan dan tingkat hasil tanaman (Widyawati, 2013).

Metode seleksi "spike to hole" merupakan seleksi tahap pertama untuk benih gandum Australia karena benih gandum dari Australia merupakan benih uji coba kali pertama di Indonesia. Metode tersebut akan dilanjutkan dengan metode seleksi "hole to block" yang dilakukan dengan menanam tanaman gandum pada kelompok lubang tanam seragam yang lolos seleksi. Modifikasi yang dilakukan bertujuan selaras dengan metode "ear to row" untuk menyempurnakan materi genetik pada tetua yang digunakan (Romadhona et al., 2014 dan Amzeri, 2019). Penelitian seleksi genotipe gandum terdahulu yang dilakukan oleh Kurnia et al., (2014), Wardani et al., (2015), dan Kadir et al., (2019), menggunakan pola galur tanam pada gandum. Metode "spike to hole" penelitian ini bertujuan untuk mengidentifikasi karakter dan melakukan seleksi pada benih gandum dari Australia.

\section{METODOLOGI PENELITIAN}

Penelitian ini dilaksanakan di Kebun Penelitian Sanghrila Fakultas Pertanian dan Bisnis Universitas Kristen 
Satya Wacana yang terletak di Dusun Jurug, Desa Wates, Kecamatan Getasan, Kabupaten Semarang - Jawa Tengah. Dilaksanakan pada 17 mei 2020 hingga 22 September 2020 dengan 1750 malai yang ditanam dan diamati. Jarak tanam yang digunakan adalah $30 \mathrm{~cm}$ x $20 \mathrm{~cm}$ pada bedengan dengan lebar $120 \mathrm{~cm}$ dengan diameter lubang tanam $7,5 \mathrm{~cm}$.

Jenis dari penelitian ini adalah deskriptif kualitatif dan didukung data kuantitatif dengan metode penelitian survey, pengamatan pertumbuhan tanaman gandum, analisis laboratorium dan tinjauan pustaka. Data diperoleh langsung dari pengamatan mengenai 10 fase pertumbuhan tanaman gandum Australia. Parameter kualitatif yang diamati dalam penelitian ini adalah lapisan lilin pada daun, warna ligula, Ada tidaknya Awn, Arah gerak awn, warna malai muda, warna malai tua, warna biji masak dan usia panen. Parameter kuantitaif yang diamati pada penelitian ini adalah tinggi akhir tanaman, populasi dan jumlai malai tanaman, panjang malai dan jumlah spikelet. Penelitian ini juga didukung pengamatan data selintas, dan secara keseluruhan data disajikan dalam dengan konsep deskriptif ekslplorasi sederhana.

\section{HASIL DAN PEMBAHASAN}

Berdasarkan penelitian yang dilakukan pada bulan Mei 2020 hingga bulan September 2020 setidaknya menghasilkan populasi yang dapat bertahan dan telah lolos seleksi sebanyak 615 hole. Proses seleksi sejak awal tanam menyisihkan 1135 hole yang tidak lolos seleksi disebabkan oleh beberapa faktor ketidak seragaman tanaman gandum, atau kerusakan parameter data pada tanaman gandum dalam satu hole.

Penyeleksian meliputi seleksi benih tidak dapat tumbuh, seleksi tanaman layu atau rusak, dan tanaman gandum yang mati. Jangka waktu penanaman hingga panen terhitung secara keseluruhan adalah 127 hari. Waktu tersebut termasuk untuk proses seleksi yang dilakukan setiap minggu sejak awal masa tanam.

Proses seleksi yang dilakukan setiap minggu juga dilakukan untuk mengamati karakter tanaman gandum pada setiap stadia dan pengamatan iklim mikro yang menjadi parameter selintas pada penelitian ini. Waktu tersebut merupakan keseluruhan waktu yang dibutuhkan untuk menyelesaikan proses panen gandum periode pertama pada 113 HST, dan panen gandum periode kedua pada 127 HST. Pada periode panen pertama dan periode panen kedua mendapatkan hasil panen dengan 2 tipe gandum yang berbeda. Parameter selintas yang diamati pada penelitian ini tersaji dalam Tabel 1.

Terjadinya perbedaan usia panen tanaman gandum diduga karena benih gandum Australia yang ditanamn pada penlitian ini masih melakukan adaptasi. Gandum tropis biasanya dapat dipanen pada usia 85HST hingga 115HST tergantung ketinggian tempat budidaya. Semakin tinggi lokasi budidaya tanaman maka akan semakin lama usia panen tanaman gandum (Puslitbang Tanaman Pangan, 2016; Widowati et al., 2016). 
Tabel 1. Parameter Selintas Penelitian Kondisi Iklim Mikro pada Lokasi Penelitian

\begin{tabular}{llcr}
\hline \multicolumn{4}{c}{ Rata-rata Suhu dan Kelembaban Per Bulan } \\
\hline No. & Bulan & Suhu $\left({ }^{\mathbf{0}} \mathbf{C}\right)$ & Kelembaban $(\boldsymbol{\%})$ \\
\hline 1. & Mei 2020 & 27,80 & 69,86 \\
\hline 2. & Juni 2020 & 27,34 & 61,73 \\
\hline 3. & Juli 2020 & 26,54 & 61,20 \\
\hline 4. & Agustus 2020 & 26,10 & 63,60 \\
\hline 5. & September 2020 & 28,38 & 70,67 \\
\hline \multicolumn{4}{c}{ Kondisi iklim mikro lokasi penelitian }
\end{tabular}

Tanaman yang tidak dapat tumbuh dapat diketahui pada 14HST, pada usia tersebut tanaman telah memasuki stadia pertumbuhan anakan. Dapat diketahui benih pada lubang tanam yang dapat tumbuh maupun yang tidak dapat tumbuh yang disebabkan kerusakan benih. Kerusakan benih dapat terjadi karena pada saat panen hingga penyimpanan memiliki kadar air yang terlalu tinggi (Andriani \& Isnaini, 2013).

Tanaman gandum yang terseleksi akibat layu yang ditandai dengan menguningnya bagian tanaman diduga karena terjadinya kompetisi antar tanaman. Pada budidaya gandum tropis biasanya digunakan jarak tanam $2-5 \mathrm{~cm}$ untuk jarak dalam baris dan 25-30 cm jarak antar baris, pada setiap baris tanam hanya ditebar 1 hingga 2 benih pada setiap titik tumbuh benih gandum. Sehingga lubang tanam berukuran diameter $7,5 \mathrm{~cm}$ dengan jarak antar lubang $20 \mathrm{~cm} \times 30 \mathrm{~cm}$ yang ditebari benih gandum satu malai utuh yang berkisar 40 benih mengakibatkan kompetisi antar tanaman gandum.

Hilangnya potensi data yang diambil pada penelitian ini juga disebabkan oleh kerusakan data yang diakibatkan oleh serangan hama tikus dan cuaca buruk yang terjadi pada stadia akhir tanaman gandum. Kerusakan data tanaman gandum yang diakibatkan oleh hama tikus menyebabkan beberapa malai pada rumpun gandum di lubang tanam berkurang dan menyisakan batang tanaman gandum.

\section{Parameter Kualitatif}

Pengambilan parameter kualitatif yang diamati pada penelitian ini meliputi lapisan lilin pada daun tanaman gandum, warna ligula, ada tidaknya $A w n$ atau buluh, arah gerak Awn, warna malai muda, warna malai tua, warna biji masak dan usia panen. Hasil pengamatan parameter kualitatif pada peneltian ini tersaji dalam Tabel 2.

Karakter daun berlilin pada gandum Australia dimiliki oleh semua genotipe yang didapat, hal ini dicirikan dengan daun yang berwarna hijau pucat sebelum tanaman gandum memasuki fase akhir atau seperti yang terlihat pada Gambar 1.

Ciri lain yang dapat dilihat daun pada tanaman gandum tidak terlihat basah Ketika terkena air melainkan memiliki efek seperti daun talas. Tanaman gandum Australia memiliki warna ligula berwarna hijau kekuningan yang terlihat pada daerah pangkal daun seperti pada Gambar 2. Keberadaan Awn atau buluh pada ujung malai gandum terdapat pada kedua tipe gandum dikedua periode panen. Arah gerak awn menunjukan arah vertikal atau mengarah keatas. Tampak visual pada malai muda di kedua tipe pada kedua periode panen 
memliki kesamaan yaitu berwarna hijau pucat. Perbedaan yang tampak adalah Ketika malai tua, pada gandum Australia tipe 1 memiliki warna kuning pucat dan pada gandum Australia memiliki warna kuning emas seperti yang dapat dilihat pada Gambar 3. Meskipun berbeda pada warna malai tua yang Nampak, tetapi warna biji masak pada gandum Australia terlihat sama yaitu memiliki warna cokelat tua.

Tabel 2. Karakter Visual dan Usia Panen Tanaman Gandum Australia

\begin{tabular}{|c|c|c|c|c|c|}
\hline \multicolumn{6}{|c|}{ Tabel Kualitatif } \\
\hline No. & Parameter & Tipe 1 & Tipe 2 & Tipe 1a & Tipe 2a \\
\hline 1 & Lapisan Lilin pada daun & Ada & Ada & Ada & Ada \\
\hline 2 & Warna Ligula & $\begin{array}{c}\text { kuning } \\
\text { kehijauan }\end{array}$ & $\begin{array}{l}\text { kuning } \\
\text { kehijauan }\end{array}$ & $\begin{array}{l}\text { kuning } \\
\text { kehijauan }\end{array}$ & $\begin{array}{l}\text { kuning } \\
\text { kehijauan }\end{array}$ \\
\hline 3 & $A w n$ & Ada & Ada & Ada & Ada \\
\hline 4 & Arah Gerak Awn & Vertikal & Vertikal & Vertikal & Vertikal \\
\hline 5 & Warna malai Muda & $\begin{array}{l}\text { Hijau } \\
\text { Pucat }\end{array}$ & $\begin{array}{l}\text { Hijau } \\
\text { Pucat }\end{array}$ & $\begin{array}{l}\text { Hijau } \\
\text { Pucat }\end{array}$ & $\begin{array}{l}\text { Hijau } \\
\text { Pucat }\end{array}$ \\
\hline 6 & Warna Malai Tua & $\begin{array}{l}\text { Kuning } \\
\text { Pucat }\end{array}$ & $\begin{array}{l}\text { Kuning } \\
\text { Emas }\end{array}$ & $\begin{array}{l}\text { Kuning } \\
\text { Pucat }\end{array}$ & $\begin{array}{l}\text { Kuning } \\
\text { Emas }\end{array}$ \\
\hline 7 & Warna Biji Masak & $\begin{array}{l}\text { Cokelat } \\
\text { Tua }\end{array}$ & $\begin{array}{l}\text { Cokelat } \\
\text { Tua }\end{array}$ & $\begin{array}{l}\text { Cokelat } \\
\text { Tua }\end{array}$ & $\begin{array}{l}\text { Cokelat } \\
\text { Tua }\end{array}$ \\
\hline 8 & Usia Panen & $113 \mathrm{HST}$ & $113 H S T$ & $127 \mathrm{HST}$ & $127 \mathrm{HST}$ \\
\hline
\end{tabular}

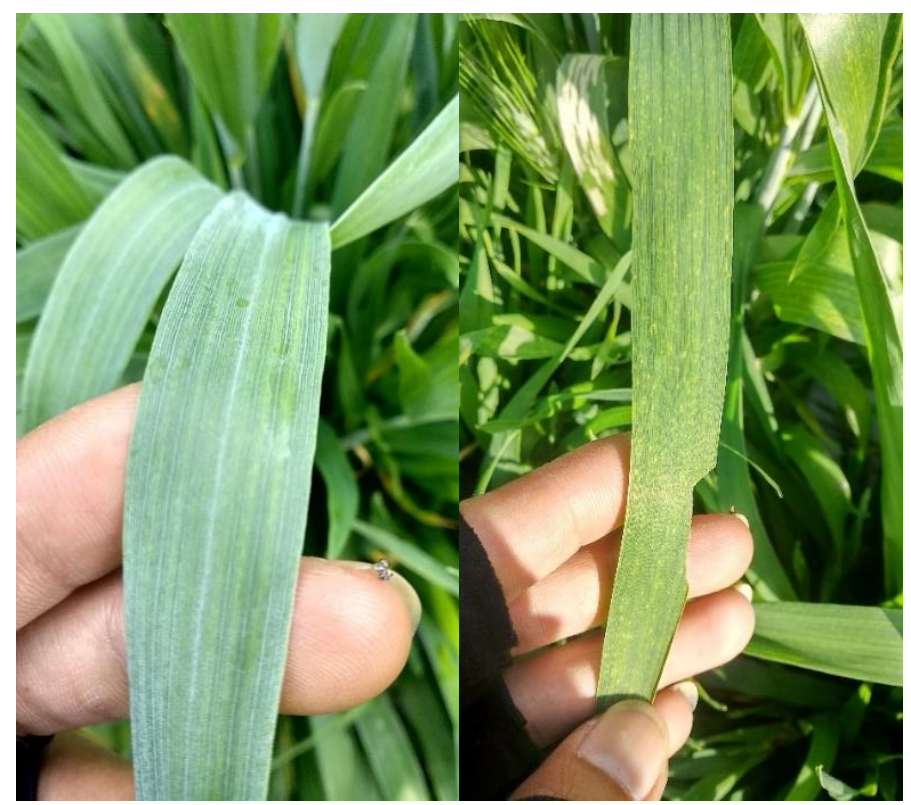

Gambar 1. Lapisan lilin pada daun gandum Australia 


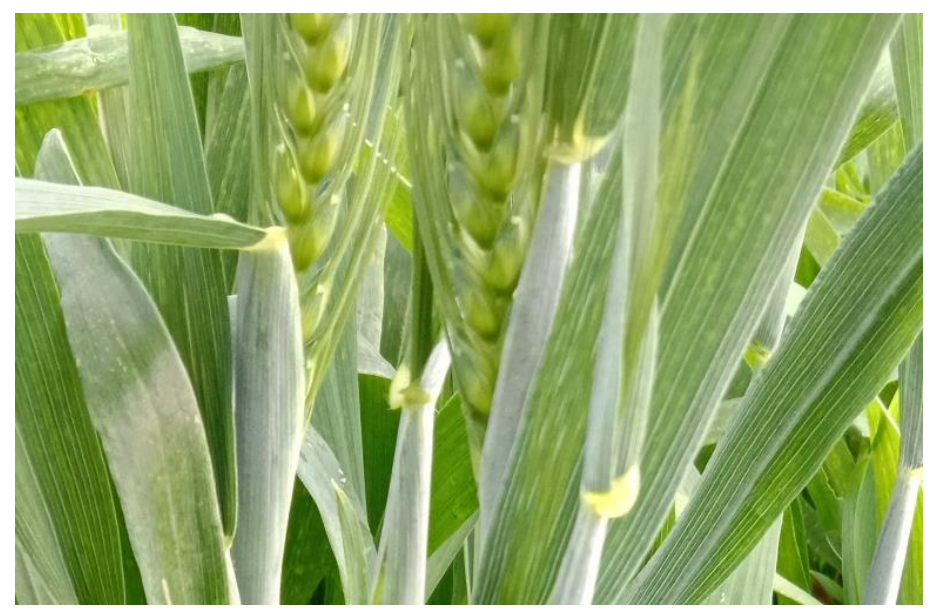

Gambar 2. Warna Ligula pada Tanaman Gandum Australia

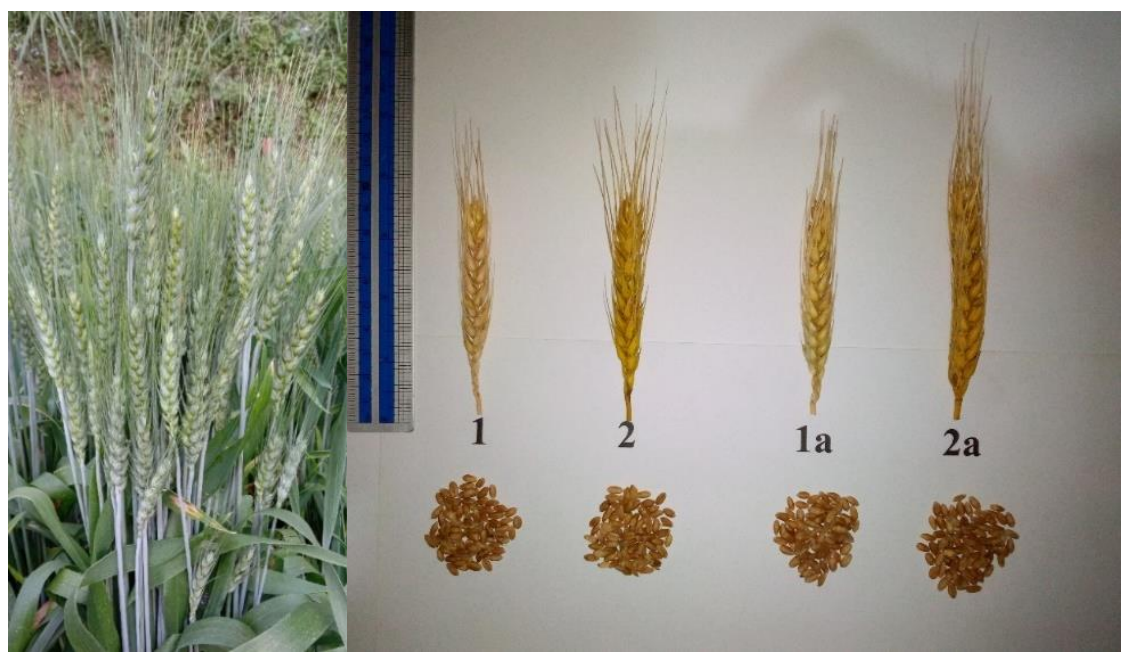

Gambar 3. Warna Malai Muda dan Malai Masak Gandum Australia

Berdasarkan ciri visual yang didapat belum ditemukan kesamaan spesifik seperti yang ada pada klasifikasi yang ditetapkan oleh (Wheat Quality Australia, 2015). Hal ini diduga karena faktor adaptasi yang terjadi pada benih gandum australia yang ditanam pada lingkungan tropis.

\section{Parameter Kuantitatif}

Pengambilan parameter kuantitatif pada penelitian ini meliputi tinggi akhir tanaman, populasi dan jumlah malai, panjang malai, dan jumlah spikelet. Parameter tersebut bertujuan untuk mengetahui ciri-ciri tanaman gandum Australia yang di tanam pada lingkungan tropis lebih spesifik melalui data kuantitatif. Parameter kuantitaif disajikan pada Tabel 3. 
Tabel 3. Data Kuantitatif Gandum Australia

\begin{tabular}{ccccccccccc}
\hline & \multicolumn{9}{c}{ Tabel Kuantitatif } \\
\hline & \multicolumn{2}{c}{ Tipe 1 } & \multicolumn{2}{c}{ Tipe 2 } & \multicolumn{2}{c}{ Tipe 1a } & \multicolumn{2}{c}{ Tipe 2a } \\
\cline { 3 - 11 } No. & Parameter & $\begin{array}{c}\text { Rata- } \\
\text { rata }\end{array}$ & St.dev & $\begin{array}{c}\text { Rata- } \\
\text { rata }\end{array}$ & St.dev & $\begin{array}{c}\text { Rata- } \\
\text { rata }\end{array}$ & St.dev & $\begin{array}{c}\text { Rata- } \\
\text { rata }\end{array}$ & St.dev \\
\hline $\mathbf{1}$ & $\begin{array}{l}\text { Tinggi Akhir } \\
\text { Tanaman }\end{array}$ & 86.97 & 3.44 & 87.85 & 4.43 & 89.50 & 5.79 & 90.08 & 4.63 \\
\hline $\mathbf{2}$ & $\begin{array}{l}\text { Populasi \& } \\
\text { Jumlah Malai }\end{array}$ & 46 & 19.96 & 42 & 15.92 & 16 & 17.14 & 39 & 17.39 \\
\hline $\mathbf{3}$ & Panjang Malai & 8.00 & 0.62 & 8.00 & 0.71 & 8.00 & 0.81 & 8.15 & 0.82 \\
\hline $\mathbf{4}$ & Jumlah Spikelet & 17 & 2.41 & 18 & 2.52 & 15 & 2.52 & 19 & 2.8 \\
\hline
\end{tabular}

Karakterisasi kuantitatif gandum Australia pada penelitian ini

Karakter tinggi tanaman pada kedua tipe gandum Australia memiliki perbedaan yang bervariasi. Berdasarkan data ada Tabel 3. Dapat dilihat bahwa tinggi tanaman yang paling tinggi adalah tipe 2 a yang memiliki rata-rata tinggi $90.08 \mathrm{~cm}$ dengan standar deviasi pada 4.63. meskipun begitu, tanaman gandum Australia yang digunakan pada penlitian ini tergolong memiliki tinggi tanaman yang lebih tinggi dibandingan gandum tropis yang sudah ditanam di Indonesia yang memiliki rata-rata tinggi optimal pada $61,08 \mathrm{~cm}$.

Tanaman gandum dapat menghasilkan malai pada setiap batang tanaman, pada batang utama akan berbeda daripada malai batang anakan. Sehingga jumlah tanaman gandum akan sama dengan jumlah malai. Berdasarkan tabel populasi dan jumlah malai, data menunjukan bahwa secara keseluruhan populasi tanaman dan jumlah malai sangat beragam. Tanaman gandum tipe 1 pada penelitian memiliki nilai rata-rata populasi lebih tinggi dibanding tanaman gandum tipe 2. Hal tersebut diduga dikarenakan tanaman gandum tipe 1 memiliki jumlah anakan yang lebih banyak dibandingkan jumlah anakan tanaman gandum tipe 2. Jumlah anakan pada tanaman gandum dipengarungi oleh kesesuaian lingkungan tumbuh tanaman gandum, dan perlakuan yang diberikan (Wicaksono et al., 2016 dan Kurnia et al., 2017).

Panjang malai pada tanaman gandum relatif seragam pada batang utama, sedangkan pada batang anakan tanaman gandum akan menghasilkan malai yang lebih pendek. Tinggi tanaman pada gandum Australia pada penelitian ini memiliki rata - rata yang tidak jauh berbeda dari beberapa jenis gandum yang pernah ditanam di wilayah tropis Indonesia. Penelitian yang dilakukan oleh Nur et al., (2010), Kurnia et al., (2015), Wahyu et al., (2013), menunjukan data panjang malai gandum berkisar antara $7,5 \mathrm{~cm}$ hingga $11 \mathrm{~cm}$. Kondisi panjang malai pada tanaman gandum dipengaruhi oleh lingkungan tumbuh, perlakuan, dan kepadatan populasi pada setiap rumpun (Widyawati, 2013).

Jumlah spikelet pada keempat tipe yang didapat dari gandum Australia pada penelitian kali ini memiliki rata - rata yang lebih tinggi dibandingkan dengan jumlah spikelet pada gandum tropis yang digunakan pada penelitian sebelumnya. Data dari penelitian yang dilakukan oleh Nur et al., (2012), Wardani et al., (2015) menunjukan data bahwa gandum tropis 
yang ditanam pada dataran tinggi hanya memiliki jumlah spikelet sebanyak 9 hingga 15 spikelet. Sedangkan pada gandum Australia yang digunakan dalam penelitian ini memiliki rata-rata jumlah spikelet terendah 15 dan memiliki ratarata nilai tertinggi adalah 19 spikelet.

\section{KESIMPULAN DAN SARAN}

\section{Kesimpulan}

Berdasarkan penelitian yang dilakukan pada benih gandum Australia yang telah ditanam pada lingkungan tropis, dapat disimpulkan bahwa karakter tanaman gandum Australia terbagi menjadi 2 tipe yang tampak secara visual dan memiliki 2 periode panen yang berbeda yaitu pada 113 HST dan 127 HST. Genotipe seragam pada gandum Australia sebanyak 615 lubang tanam yang terkelompokan menjadi 4 tipe gandum yaitu gandum dengan warna malai masak berwarna kuning pucat periode 1 (tipe 1), gandum dengan warna malai masak berwarna kuning emas periode 1 (tipe 2), gandum dengan warna malai masak berwarna kuning pucat periode 2 (tipe 1a), gandum dengan warna malai masak berwarna kuning emas periode 2 (tipe $2 a$ ).

\section{Saran}

Beberapa kekurangan dalam penelitian ini dengan penerapan pola tanam "spike to hole" memberikan saran untuk meningkatkan penelitian lanjutan untuk mendapatkan genotipe unggul dari pengembangan gandum Australia pada wilayah tropis. Saran tersebut disampaikan pada beberapa poin berikut:

1. Perlunya perubahan metode malai ke lubang menjadi malai baris tanam untuk penelitian lanjutan dengan jarak tanam standar antara jarak dalam baris $(5 \mathrm{~cm})$ dan jarak antar baris $(25 \mathrm{~cm})$ agar kepadatan populasi gandum tidak terlalu tinggi.

2. Pemberian perlakuan untuk mengendalikan OPT agar tanaman gandum dapat tumbuh dengan baik.

3. Penambahan parameter umur per stadia agar dapat menjabarkan keberlangsungan stadia gandum pada hari setelah tanam (HST).

4. Perlunya dilakukan pemgukuran bobot sampel untuk mengetahui potensi hasil dari setiap tipe.

Perlunya analisa warna tepung biji gandum agar dapat dilakukan pendekatan klasifikasi sesuai standar yang berlaku pada Wheat Quality Australia, (2015).

\section{UCAPAN TERIMAKASIH}

Peneliti mengucapkan terimakasih kepada Pusat Studi Gandum Fakultas Pertanian dan Bisnis Universitas Kristen Satya Wacana yang telah melakukan pendampingan dalam melakukan penelitian ini.

\section{DAFTAR PUSTAKA}

Amzeri, A. (2019). Seleksi Satu Tongkol Satu Baris (Ear to Row Selection) pada Tanaman Jagung (Zea mays L.). Journal of Science and Technology, 12(1), 18-23. https://doi.org/10.21107/rekayasa. v12i1.5228

Andriani, A., \& Isnaini, M. (2013). Morfologi dan Fase Pertumbuhan Gandum. Balai Penelitian Tanaman Pangan, 2(2), 69-106.

Kadir, M., Kaimuddin, K., Musa, Y., Farid, M., Syahruddin, K., \& Nur, 
A. (2019). Seleksi Genotipe Gandum Tropis Toleran Suhu Tinggi Menggunakan Marka SSR. Jurnal Ilmiah Inovasi, 19(2), 6166.

https://doi.org/10.25047/jii.v19i2.1 498

Kurnia, T. D., Murdono, D., Widyawati, N., \& Priyanto, S. H. (2014). Seleksi Ketahanan 10 Genotipe Gandum (Triticum aestivum L.) dengan Proline sebagai Penanda Terhadap Cekaman Suhu Tinggi dan Kekeringan. Prosiding Seminar Nasional Bioteknologi, 1(1), 1-9.

Puslitbang Tanaman Pangan. (2016). Gandum - Peluang Pengembangan di Indonesia (R. H. Praptana \& Hermanto (eds.)). IAARD PRESS.

Romadhona, R. F., Basunanda, P., \&
Murti, R. H. (2014). Perbandingan Kemajuan Genetis Seleksi Massa dan Tongkol - Ke Baris pada Populasi Generasi Ketiga Persarian Bebas jagung Hibrida (Zea Mays L.). Vegetalika, 3(2), 72-84.

Wardani, S., Wirnas, D., \& Wahyu, Y. (2015). Seleksi Segregan Gandum (Triticum aestivum L.) pada Dataran Tinggi. Jurnal Agronomi Indonesia, 43(1), 45-51.

Wheat Quality Australia. (2015). Wheat Classification Guidelines (Issue October).

Widowati, S., Khumaida, N., Ardie, S. W., \& Trikoesoemaningtyas. (2016). Karakterisasi Morfologi dan Sifat Kuantitatif Gandum ( Triticum aestivum L .) di Dataran Menengah. Jurnal Agron Indonesia, 44(2), 162-169. 